\title{
Front Matter: Volume 7036
}

, "Front Matter: Volume 7036," Proc. SPIE 7036, Spintronics, 703601 (29 September 2008); doi: 10.1117/12.806036

SPIE Event: NanoScience + Engineering, 2008, San Diego, California, United SPIE. States 


\section{PROCEEDINGS OF SPIE}

\section{Spintronics}

Manijeh Razeghi

Henri-Jean M. Drouhin

Jean-Eric Wegrowe

Editors

10-14 August 2008

San Diego, California, USA

Sponsored and Published by

SPIE

Volume 7036

Proceedings of SPIE, 0277-786X, v. 7036 
The papers included in this volume were part of the technical conference cited on the cover and title page. Papers were selected and subject to review by the editors and conference program committee. Some conference presentations may not be available for publication. The papers published in these proceedings reflect the work and thoughts of the authors and are published herein as submitted. The publisher is not responsible for the validity of the information or for any outcomes resulting from reliance thereon.

Please use the following format to cite material from this book:

Author(s), "Title of Paper," in Spintronics, edited by Manijeh Razeghi, Henri-Jean M. Drouhin, Jean-Eric Wegrowe, Proceedings of SPIE Vol. 7036 (SPIE, Bellingham, WA, 2008) Article CID Number.

ISSN 0277-786X

ISBN 9780819472564

Published by

SPIE

P.O. Box 10, Bellingham, Washington 98227-0010 USA

Telephone +1 3606763290 (Pacific Time) · Fax +1 3606471445

SPIE.org

Copyright (C 2008, Society of Photo-Optical Instrumentation Engineers

Copying of material in this book for internal or personal use, or for the internal or personal use of specific clients, beyond the fair use provisions granted by the U.S. Copyright Law is authorized by SPIE subject to payment of copying fees. The Transactional Reporting Service base fee for this volume is $\$ 18.00$ per article (or portion thereof), which should be paid directly to the Copyright Clearance Center (CCC), 222 Rosewood Drive, Danvers, MA 01923. Payment may also be made electronically through CCC Online at copyright.com. Other copying for republication, resale, advertising or promotion, or any form of systematic or multiple reproduction of any material in this book is prohibited except with permission in writing from the publisher. The CCC fee code is $0277-786 \mathrm{X} / 08 / \$ 18.00$.

Printed in the United States of America.

Publication of record for individual papers is online in the SPIE Digital Library.

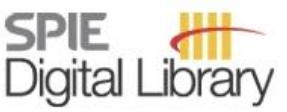

SPIEDigitallibrary.org

Paper Numbering: Proceedings of SPIE follow an e-First publication model, with papers published first online and then in print and on CD-ROM. Papers are published as they are submitted and meet publication criteria. A unique, consistent, permanent citation identifier (CID) number is assigned to each article at the time of the first publication. Utilization of CIDs allows articles to be fully citable as soon they are published online, and connects the same identifier to all online, print, and electronic versions of the publication. SPIE uses a six-digit CID article numbering system in which:

- The first four digits correspond to the SPIE volume number.

- The last two digits indicate publication order within the volume using a Base 36 numbering system employing both numerals and letters. These two-number sets start with 00, 01, 02, 03, 04, 05, $06,07,08,09,0 A, 0 B \ldots 0 Z$, followed by $10-12,20-2 Z$, etc.

The CID number appears on each page of the manuscript. The complete citation is used on the first page, and an abbreviated version on subsequent pages. Numbers in the index correspond to the last two digits of the six-digit CID number. 


\section{Contents}

vii Conference Committee

xi Introduction

xiii Revivals of molecular nonlinear optics in physics, chemistry, and life sciences (Plenary Paper) [7040-100]

J. Zyss, Lab. de Photonique Quantique et Moléculaire, CNRS, Institut d'Alembert (France)

\section{NANOPILLARS DYNAMICS}

703605 Toward antiferromagnetic metal spintronics (Invited Paper) [7036-04]

J. Basset, Univ. of Texas at Austin (United States) and Univ. Joseph Fourier, Grenoble (France); A. Sharma, Michigan State Univ. (United States); Z. Wei, Univ. of Texas at Austin (United States); J. Bass, Michigan State Univ. (United States); M. Tsoi, Univ. of Texas at Austin (United States)

\section{EXPERIMENTS, THEORY, FUNDAMENTALS OF SPIN TRANSFER ANATOMY}

703606 Morphology- and quantum-size induced oscillations of the electron-spin precession in Fe films on Ag(001) (Invited Paper) [7036-05]

L. Tati Bismaths, Institut de Physique et Chimie des Matériaux de Strasbourg, ULP, CNRS (France); L. Joly, Paul Scherrer Institut, Swiss Light Source (Switzerland); A. Bourzami, F. Scheurer, W. Weber, Institut de Physique et Chimie des Matériaux de Strasbourg, ULP, CNRS (France)

703607 DC electrical response and impedance change induced by a microwave signal in a patterned ferromagnetic wire (Invited Paper) [7036-06]

A. Yamaguchi, Keio Univ. (Japan) and PRESTO, JST (Japan); K. Motoi, Keio Univ. (Japan); A. Hirohata, Univ. of York (United Kingdom); N. Higashio, H. Miyajima, Keio Univ. (Japan)

\section{SPIN TRANSFER PHENOMENA}

703609 Diffusive spin-transfer: a derivation of the critical current from the spin-accumulation (Invited Paper) [7036-08]

J.-E. Wegrowe, H.-J. Drouhin, Lab. des Solides Irradiés, Ecole Polytechnique (France)

7036 OA Spin pumping of current in non-uniform conducting magnets (Invited Paper) [7036-09] W. M. Saslow, Texas A\&M Univ. (United States)

$7036 \mathrm{OB} \quad$ Fokker-Planck theory of spin-torque switching: effective energy and transition-state rate theory (Invited Paper) [7036-10]

P. B. Visscher, The Univ. of Alabama (United States) 
7036 Ol Optical initialisation and control of carrier and nuclear spins in individual semiconductor quantum dots (Invited Paper) [7036-17]

X. Marie, Univ. de Toulouse, LPCNO, INSA-CNRS-UPS (France); O. Krebs, Lab. de Photonique et de Nanostructures (France); B. Urbaszek, T. Belhadj, C.-M. Simon, Univ. de Toulouse, LPCNO, INSA-CNRS-UPS (France); A. Lemaitre, P. Voisin, Lab. de Photonique et de Nanostructures (France); T. Amand, Univ. de Toulouse, LPCNO, INSA-CNRS-UPS (France)

7036 0J Spin and symmetry in optical studies of individual semiconductor quantum dots (Invited Paper) [7036-18]

J. A. Gaj, T. Kazimierczuk, K. Kowalik, J. Suffczyński, A. Golnik, P. Kossacki, M. Nawrocki, Univ. of Warsaw (Poland)

\section{SPIN AND SYMMETRY FILTERING}

7036 OM Spin-dependent tunneling through a spin-orbit-split barrier (Invited Paper) [7036-21] H.-J. Drouhin, Ecole Polytechnique, LSI, CNRS et CEA, DSM, DRECAM (France); G. Fishman, Univ. Paris-Sud, IEF, CNRS (France); T. L. H. Nguyen, Ecole Polytechnique, LSI, CNRS et CEA, DSM, DRECAM (France) and Univ. Paris-Sud, IEF, CNRS (France); J.-E. Wegrowe, Ecole Polytechnique, LSI, CNRS et CEA, DSM, DRECAM (France)

\section{SPIN AND CHARGE CURRENTS}

7036 OR Spin Hall Effect (Keynote Paper) [7036-26]

M. I. Dyakonov, Univ. Montpellier II, CNRS (France)

\section{MULTIFERROICS/PEROVSKITES}

7036 OU Hybrid magnetic tunnel junction/spin filter device (Invited Paper) [7036-29]

Y. Suzuki, B. Nelson-Cheeseman, F. Wong, R. Chopdekar, Univ. of California, Berkeley (United States) and Lawrence Berkeley National Lab. (United States); E. Arenholz, Lawrence Berkeley National Lab. (United States)

\section{SPIN ENGINEERING/DEVICES}

7036 0X Electrically controlled magnetism (Invited Paper) [7036-32]

C. Binek, X. He, Y. Wang, S. Sahoo, Univ. of Nebraska, Lincoln (United States)

\section{VORTEX/DOMAIN WALLS}

703610 Single domain to vortex state transition in multilayered cobalt/copper nanowires (Invited Paper) [7036-35]

J. Wong, P. Greene, R. K. Dumas, K. Liu, Univ. of California, Davis (United States) 
703614 Novel spintronic devices using local anisotropy engineering in (Ga,Mn)As (Invited Paper) [7036-39]

C. Gould, G. Schmidt, L. W. Molenkamp, Univ. Würzburg (Germany)

703615 From diluted magnetic semiconductors to self-organized nanocolumns of GeMn in germanium (Invited Paper) [7036-40]

S. Tardif, Institut Néel, CNRS-UJF (France); I.-S. Yu, T. Devillers, M. Jamet, INAC, CEAGrenoble (France); S. Cherifi, J. Cibert, Institut Néel, CNRS-UJF (France); A. Barski,

P. Bayle-Guillemaud, E. Bellet-Amalric, INAC, CEA-Grenoble (France)

\section{DOMAIN WALLS}

703617 Lorentz microscopy and electron holography studies of current-excited magnetization dynamics in Permalloy nanowires (Invited Paper) [7036-42]

Y. Togawa, The Institute of Physical and Chemical Research, RIKEN (Japan); T. Kimura, RIKEN-The Institute of Physical and Chemical Research (Japan) and Univ. of Tokyo (Japan); K. Harada, Hitachi, Ltd. (Japan); T. Akashi, Hitachi High-Technologies (Japan); T. Matsuda, Hitachi, Ltd. (Japan); A. Tonomura, RIKEN-The Institute of Physical and Chemical Research (Japan) and Hitachi, Ltd. (Japan); Y. Otani, RIKEN-The Institute of Physical and Chemical Research (Japan) and Univ. of Tokyo (Japan)

\section{SPIN MANIPULATION}

7036 1A Manipulation of individual electronic spins in semiconductors (Invited Paper) [7036-45] C. E. Pryor, J. Pingenot, A. De, M. E. Flatté, Univ. of lowa (United States)

7036 1B Pure spin-current-induced magnetization switching (Invited Paper) [7036-46]

T. Yang, The Institute of Physical and Chemical Research, RIKEN (Japan); T. Kimura, RIKENThe Institute of Physical and Chemical Research (Japan) and Univ. of Tokyo (Japan); J.-B. Laloë, RIKEN-The Institute of Physical and Chemical Research (Japan); Y. Otani, RIKEN-The Institute of Physical and Chemical Research (Japan) and Univ. Of Tokyo (Japan)

DOMAIN WALLS, METAL/SEMICONDUCTOR STRUCTURES

7036 IE Analysis of nonlinear dynamics and spin-flip parameters on elliptically polarized injectionlocked VCSELs [7036-49]

A. Homayounfar, M. J. Adams, Univ. of Essex (United Kingdom)

Author Index 
Downloaded From: https://www.spiedigitallibrary.org/conference-proceedings-of-spie on 26 Apr 2023

Terms of Use: https://www.spiedigitallibrary.org/terms-of-use 


\title{
Conference Committee
}

\author{
Symposium Chairs
}

David L. Andrews, University of East Anglia Norwich (United Kingdom) James G. Grote, Air Force Research Laboratory (United States)

Kevin J. Liddane, Oerlikon Optics USA Inc. (United States)

Conference Chairs

Manijeh Razeghi, Northwestern University (United States)

Henri-Jean M. Drouhin, École Polytechnique (France)

Jean-Eric Wegrowe, École Polytechnique (France)

Program Committee

Jack Bass, Michigan State University (United States)

Michael E. Flatté, The University of lowa (United States)

Henri Jaffrès, Unité Mixte de Physique, CNRS/Thales (France)

Mathias Michael Kläui, Universität Konstanz (Germany)

Yuri A. Mamaev, St. Petersburg State Technical University (Russia)

Ryan P. McClintock, Northwestern University (United States)

Laurens W. Molenkamp, Universität Würzburg (Germany)

Jean-Pierre Nozières, Crocus Technology (France)

Yoshichika Otani, RIKEN-The Institute of Physical and Chemical Research (Japan)

Jing Shi, University of California, Riverside (United States)

Donald J. Silversmith, Air Force Office of Scientific Research (United States)

Luc Thomas, IBM Almaden Research Center (United States)

Evgeny Tsymbal, University of Nebraska-Lincoln (United States)

Jörg Wunderlich, Hitachi Cavendish Laboratory (United Kingdom)

\section{Session Chairs}

$1 \quad$ Nanopillars Dynamics

Luc Thomas, IBM Almaden Research Center (United States)

Mark D. Stiles, National Institute of Standards and Technology (United States)

2 Experiments, Theory, Fundamentals of Spin Transfer Anatomy

Mathias Klaevi, Universität Konstanz (Germany)

William Rippard, National Institute of Standards and Technology

(United States) 
3 Spin Transfer Phenomena

Jack Bass, Michigan State University (United States)

Akinobu Yamaguchi, Keio University (Japan)

$4 \quad$ Current-induced Magnetization Reversal

Jean-Eric Wegrowe, Ecole Polytechnique (France)

Brad N. Engel, Freescale Semiconductor, Inc. (United States)

$5 \quad$ Magnetic Semiconductor Heterostructures

Henri Jaffrès, Unité Mixte de Physique, CNRS/Thales (France)

Hideo Ohno, Tohoku University (Japan)

$6 \quad$ Spintronics with Quantum Dots

Yoshichika Otani, RIKEN-The Institute of Physical and Chemical Research (Japan)

Michel I. Dyakonov, Université Montpellier II (France)

$7 \quad$ Spin and Symmetry Filtering

Joël Cibert, Centre National de la Recherche Scientifique (France)

Kai Liu, University of California, Davis (United States)

8 Carbon-based Spintronics

Michael E. Flatté, The University of lowa (United States)

Tomas Jungwirth, Institute of Physics v.v.i. ASCR (Czech Republic)

9 Spin and Charge Currents

Manijeh Razeghi, Northwestern University (United States)

Jan A. Gaj, University Warszawski (Poland)

10 Multiferroics/Perovskites

Neil D. Mathur, University of Cambridge (United Kingdom)

11 Spin Engineering/Devices

Henri-Jean M. Drouhin, Ecole Polytechnique (France)

Guido Meier, Universität Hamburg (Germany)

12 Vortex/Domain Walls

Csaba Jozsa, University of Groningen (Netherlands)

Julie Grollier, Unité Mixte de Physique, CNRS/Thales (France)

13 Magnetic Semiconductor Heterostructures

Jing Shi, University of California, Riverside (United States)

Masaaki Tanaka, The University of Tokyo (Japan) 
14 Domain Walls

Alain Schuhl, Commissariat à l'Energie Atomique (France)

Matthias Bode, Argonne National Laboratory (United States)

15 Spin Manipulation

Julie Grollier, Thales Research and Technology (France)

Jean-Marc Jancu, Laboratoire de Photonique et de Nanostructures, CNRS (France)

16 Domain Walls, Metal/Semiconductor Structures

Wolfgang Weber, Université Louis Pasteur (France)

Eric E. Fullerton, University of California, San Diego (United States) 
Downloaded From: https://www.spiedigitallibrary.org/conference-proceedings-of-spie on 26 Apr 2023

Terms of Use: https://www.spiedigitallibrary.org/terms-of-use 


\section{Introduction}

This 2008 Spintronics Conference in San Diego, CA (August 10-14) is the first edition of a whole Symposium devoted to solid-state spin physics inside the well known SPIE event. About 50 renowned scientists participated in this meeting, presenting 3 keynotes lectures and 42 invited talks. Presentations and discussions were a nice occasion to set the State of the Art in this rapidly evolving field of spintronics.

The conference covered many hot topics in spin-dependent metal physics or in spin-dependent semiconductor physics, ranging from fundamental aspects to applications. The keynote lectures of Profs. Michel Dyakonov, Masaaki Tanaka and Hideo Ohno, together with many other important contributions, allowed a large panorama to be drawn on semiconductor spintronics. Also, a large part of the conference was devoted to the spin transfer effects studied on various kinds of structures and observed with the help of new experimental techniques. The large number of original experimental and theoretical developments presented at this meeting confirms the impression of rapid and fruitful progress in this new field of investigation.

Overall, the conference was an invaluable opportunity for open exchange and stimulating discussions in a friendly atmosphere. This proceedings volume includes a significant number of these contributions, thus providing extremely useful references.

We are grateful to SPIE, the Organizing Committee, and the authors that have made the conference a success. 